\title{
RADIATION-INDUCED DISEASES: ASSESSMENT OF THE CANCER RISKS OF LOW-LEVEL IONIZING RADIATION EXPOSURE
}

\author{
BY S. HABERMAN
}

(Paper No. 35 deposited in the Library in April 1984)

THIS research memorandum has been written in response to a remit to the Government Actuary's Department from the Industrial Injuries Advisory Council (IIAC). The IIAC are reviewing the terms under which radiationinduced diseases are prescribed as industrial diseases and, as part of this process, have invited evidence from a number of organizations and individuals. Evidence has been submitted by Dr Alice Stewart (Department of Social Medicine, University of Birmingham) based on her analyses of results from the long-term cohort study of workers exposed to low-level radiation at the Hanford Works, Washington, U.S.A.

The Hanford Works is one of the largest nuclear plants in the U.S.A. and has been in full production since 1944. About 30,000 persons have worked at Hanford and up to 1977 there had been about 4,200 deaths among current and ex-employees.

Some of the methodology adopted by Dr Stewart and her colleagues is controversial and has attached scientific criticism. However, it is their results which have received wide publicity and stimulated a heated debate. Their first paper, for example, 'shows' that low-level radiation has a strong, positive cancer induction effect with the risk of death from radiation-induced cancer being estimated at about ten times the level of the conventional International Commission on Radiological Protection (ICRP) estimates. Subsequent papers from Dr Stewart and her colleagues have refined these estimates.

The purpose of this research memorandum is to comment critically on the literature surrounding the Hanford investigations (over 60 papers and letters) and, in particular, advise on the soundness of Dr Stewart's methodology and results.

The conclusions of this review are that the published works of Dr Stewart and her colleagues do not represent valid statistical analyses or interpretations of the actual observations. This does not mean that there are no excess cancer risks from low-level radiation-just that the case has not been proven either way. Indeed, there is a problem of statistical power. Any investigation into the effect of low-level radiation at work is very likely to involve insufficient data to increase adequately the statistical power of the study. This means that it may be impossible, in a practical sense, to determine definitively whether the risks of low-level ionizing radiation are significantly higher than the conventional ICRP recommendations. 